\title{
ROTULAÇÃO E SELETIVIDADE POLICIAL: ÓBICES À INSTITUCIONALIZAÇÃO DA DEMOCRACIA NO BRASIL
}

\author{
Etiquetamiento y Selectividad Policial: óbices a la \\ institucionalización de la democracia en Brasil \\ Labeling and Police Selectivity: obstacles to the \\ institutionalization of democracy in Brazil
}

FLÁVIA CRISTINA SOARES

Universidade Federal de Minas Gerais /UFMG, Belo Horizonte - MG, Brasil

LUDMILA MENDONÇA LOPES RIBEIRO

Universidade Federal de Minas Gerais /UFMG, Departamento de Sociologia (DSO), Belo Horizonte - MG, Brasil

http://dx.doi.org/10.1590/S2178-14942018000100006

Doutoranda em Sociologia pela Universidade Federal de Minas Gerais (UFMG). Mestre em Sociologia pela Universidade Federal de Minas Gerais - UFMG (2013). Especialista em Gestão Social pela Escola de Governo da Fundação João Pinheiro (2010). (flavia.c.soarez@gmail.com)

Possui doutorado em Sociologia pelo Instituto Universitário de Pesquisas do Rio de Janeiro - IUPERJ (2009), com estágio na University of Florida (2007/2008), mestrado em Administração Pública pela Fundação João Pinheiro (2003), graduação em Direito pela Universidade Federal de Minas Gerais (2002) e graduação em Administração Pública pela Fundação João Pinheiro (2001). (ludmila.ribeiro@gmail.com) 
Artigo recebido em 29 de setembro de 2017 e aprovado para publicação em 15 de dezembro de 2017.

\section{RESUMO:}

Este artigo apresenta uma revisão dos estudos produzidos no Brasil, a partir da teoria da rotulação, sobre o funcionamento do sistema da justiça criminal, com destaque para as ações policiais. 0 balanço da literatura indica que os indivíduos jovens, negros e pobres são os mais suscetíveis ao rótulo de criminoso pelas polícias e pelo Poder Judiciário, institucionalizando a cidadania disjuntiva. Os resultados permitiram concluir que há um descompasso entre o ideal da democracia e a realidade construída por meio das instituições que são encarregadas da produção da justiça no país, contribuindo para a reificação de desigualdades sociais, fato que bloqueia o desenvolvimento da democracia.

PALAVRAS-CHAVE: Teoria da rotulação; Democracia; Instituições; Sistema de justiça criminal.

\section{RESUMEN}

Este artículo presenta una revisión de los estudios producidos en Brasil, a partir de la teoría del etiquetamiento, sobre el funcionamiento del sistema de justicia criminal, con énfasis en las acciones policiales. El balance de la literatura indica que los individuos jóvenes, negros y pobres son los más susceptibles etiquetamiento como criminales por las policías y el poder judicial, institucionalizando la ciudadanía disyuntiva. Los resultados permitieron concluir que hay un desequilibrio entre el ideal de la democracia y la realidad construida por medio de las instituciones que se encargan de la producción de la justicia en el país, contribuyendo a la reificación de desigualdades sociales, hecho que bloquea el desarrollo de la democracia en el país.

PALABRAS-ClAVE: Teoría de la rotulación; Democracia; Instituciones; Sistema de justicia penal.

\section{ABSTRACT}

Through the perspective of the labeling theory, this paper presents a review of the studies produced in Brazil, about the functioning of the criminal justice system, with an emphasis on police actions. The literature review indicates that young, black and poor individuals are the most susceptible to be labeled as criminals by the police and the judiciary, institutionalizing the disjunctive citizenship. The results enabled us to conclude that there is a mismatch between the ideal of democracy and the reality built through the institutions that are in charge of the production of justice in the country, contributing to the reification of social inequalities, a fact that hinders the development of democracy in the country.

KEYWORDS: Labeling theory; Democracy; Institutions; Criminal justice system. 


\section{INTRODUÇÃO}

E ste artigo tem como objetivo apresentar como as instituições do sistema de justiça criminal produzem o crime e o criminoso de forma seletiva, fato que bloqueia a institucionalização da democracia no Brasil contemporâneo. Para tanto, serão revisados os estudos internacionais e nacionais que foram produzidos a partir da teoria da rotulação ou labeling theory. ${ }^{1}$ Tal perspectiva obteve visibilidade nos Estados Unidos, nos anos 1960, sendo que sua receptividade no Brasil se deu pelos estudos de Howard Becker (Werneck, 2014). Desde então, essa teoria tem se tornado um artifício metodológico utilizado para o entendimento de como as interações entre os profissionais do sistema de justiça criminal e determinadas classes de cidadãos reificam as desigualdades sociais (Carvalho, 2008), ao contrário do que seria a sua missão: tornar iguais, em termos de acesso a direitos, indivíduos que são economicamente desiguais (Kant de Lima, 2001).

Na sociologia da administração da justiça, a perspectiva da rotulação se dissemina no País, a partir da década de 1980, com os trabalhos de Campos Coelho e Paixão, interessados na problemática da criminalidade urbana e na seletividade do funcionamento dos órgãos do sistema de justiça criminal. A influência da labeling theory produziu uma inflexão no campo dos estudos sobre o crime, sobretudo no que diz respeito ao uso dos dados produzidos pela polícia e no entendimento sobre a correlação entre crime e pobreza. Por meio desses trabaIhos, constituiu-se uma linha de pesquisa denominada sociologia da administração da justiça (Azevedo, 2014), que procura compreender as causas e as consequências desse funcionamento seletivo (Vargas, 2014; Sinhoretto, 2014).

Nas seções a seguir, a teoria da rotulação, na versão formulada por Becker, e suas influências sobre as pesquisas atuais no campo da sociologia da administração da justiça serão apresentadas. Será destacado o funcionamento seletivo da porta de entrada do sistema, pelo poder da polícia "em exercer uma vigilância mais cerrada sobre as pessoas de status mais baixo e efetuar prisões baseadas em evidências mais fluidas do que ela pode" (Paixão, 1995: 6), o que dá lugar à cristalização da cidadania disjuntiva, já que os requisitos formais, que qualificariam o Brasil como País democrático, convivem com casos cotidianos de injustiça, violência e impunidade, em suma, de desrespeito aos direitos humanos (Holston; Caldeira, 1999: 692).

\section{NOTAS SOBRE A DEMOCRACIA E O SISTEMA DE JUSTIÇA CRIMINAL}

m ponto de partida para se pensar a interseção entre história, democracia e justiça criminal é o ensaio de T. H. Marshall, intitulado "Cidadania, classe social e status", no qual 
ele procura desvelar em que medida a desigualdade de ocupação (desigualdade econômica) pode não significar desigualdade de inserção social (desigualdade de cidadania), a partir do funcionamento de uma série de instituições estatais.

Para explicar como a desigualdade de renda seria compensada por uma igualdade jurídica, Marshall (1967) estrutura o conceito de cidadania a partir de três elementos, que encontram ressonância em instituições distintas, essenciais para a formação de uma sociedade democrática. 0 elemento civil diz respeito às liberdades individuais, tendo como correlato o direito de se defender e afirmar seus direitos perante os tribunais de justiça. 0 elemento político, que significa a possibilidade de participar das mais diversas organizações e eleger os responsáveis pelo governo da sociedade, teria nos parlamentos e no Governo local suas instituições de destaque. Por fim, o elemento social, refere-se ao bem-estar do indivíduo na sociedade e tem como instituições correspondentes o sistema educacional e os serviços sociais. Na análise desenvolvida pelo autor, é impossível conceber uma sociedade como democrática quando a cidadania ainda não se encontra consolidada em suas dimensões civil, política e social. Afinal, "a cidadania é um status concedido àqueles que são membros integrais de uma comunidade. Todos aqueles que possuem o status são iguais com respeito aos direitos e obrigações pertinentes ao status" (Marshall, 1967: 76).

Interessante notar o papel do sistema de justiça nessa equação. A inovação apresentada pelas instituições de justiça, já no fim do século XVIII, era o reconhecimento do direito como algo que se sobrepunha aos interesses de determinados grupos sociais. Marshall descreve como, no contexto inglês, os tribunais de justiça vão progressivamente interpretando as legislações escritas de forma a tornar os homens menos dependentes do status dado pelo nascimento, quando da celebração de diversos contratos, inclusive o de trabalho, o que progressivamente os tornaria mais igualitários e livres das amarras decorrentes de seu sangue. Ainda que a lei seja desigual em sua origem, a forma como os operadores a interpretam e deliberam os casos fazem com que esses dispositivos se transformem em instrumentos de produção de igualdade jurídica.

Na análise realizada por Marshall (1967), só existe uma sociedade democrática se existir cidadania, sendo que esta será viável se as instituições de justiça forem capazes de operar de forma a tornar indivíduos economicamente desiguais em indivíduos juridicamente igualitários. No Brasil, há uma reversão dos princípios que orientam a dimensão civil da cidadania. Em vez de as instituições do sistema de justiça servirem para equalizar problemas decorrentes do status socioeconômico dos indivíduos, como a instância que corrige as desigualdades dadas pelo nascimento, elas têm uma operação reversa. As instituições de justiça reificam as 
desigualdades de classe quando não são responsáveis por sua produção, fazendo do Brasil um exemplo visível de "distribuição da desigualdade e da injustiça" (Holston, 2013: 56). É certo que, em algumas circunstâncias esse sistema opera tal como teoricamente se espera, mas esses casos são tão raros que podem ser identificados pontualmente (Azevedo, 2014).

Em terras tupiniquins, as leis são escritas por notáveis e depois interpretadas por esses mesmos indivíduos, o que permite uma enorme diferenciação de como um mesmo dispositivo será compreendido, dependendo de quem o aciona (Kant de Lima, 2001). Ao contrário da presunção de Marshall, de que o sistema de justiça serviria para atenuar as desigualdades dadas pelo nascimento, no Brasil, a justiça tem enorme maleabilidade, de forma a garantir que indivíduos distintos, quando pleiteando o mesmo direito, recebam decisões diferenciadas. Por isso, diz-se que, aqui entre nós, "a lei está para ser usada seletivamente: para nossos amigos, a amizade; para nossos inimigos, a lei" (Shirley, 1987: 89), denotando a enorme lacuna entre o direito formal e 0 aplicado, sendo que a consequência mais nefasta é o fato de que "os brasileiros simplesmente não acreditam na lei" como uma forma de mediação de seus problemas (Shirley, 1987: 89).

Várias são as análises existentes sobre os efeitos que a administração seletiva da justiça têm sobre a qualidade da cidadania, bloqueando a institucionalização da democracia em nosso País. Holston e Caldeira (1999) entendem que a cidadania cristalizada no Brasil pode ser qualificada como disjuntiva, dada a incapacidade de os tribunais transformarem as previsões legais em realidade ou a enorme maleabilidade interpretativa dessas instâncias, produzindo desigualdade e injustiça. Holston (2013) sublinha como a apreciação da qualidade da cidadania no Brasil deve se orientar pelo pressuposto de que a administração da justiça muitas vezes segue interesses econômicos ou interesses relacionados aos status dos indivíduos, o que termina por subverter a promessa de igualdade.

Para Kant de Lima (2001), o sistema de justiça brasileiro existe para ser um mecanismo de controle de uma determinada camada da população, aquela que precisa acessar o Estado. É a partir desse modelo de operação que esse sistema produz cidadanias de densidades tão diferenciadas que podem ser acomodadas em uma estrutura piramidal. Os indivíduos que estão no topo podem orientar a ação do Estado em direção ao controle da base, fazendo com que o status econômico não seja radicalmente alterado, com o passar dos anos, pela ação dos tribunais (Kant de Lima, 2001). Ao se estruturar dessa maneira, esse sistema faz com que "a igualdade absoluta constitucionalmente garantida a todos os cidadãos conviva com os sistemas classificatórios e discriminadores da ação estatal" (Paixão, 1988: 175).

Sinhoretto (2010) discorre sobre como essa forma de operação do sistema de justiça garante a desigualdade pela análise dos "quatro níveis de intensidade" da qualidade das de- 
cisões. O ponto de partida de seu exame é o dilema vivenciado pela sociedade brasileira, que combina uma série de "práticas sociais hierárquicas - em que cada um tem o seu lugar, com direitos e deveres particulares - e uma representação das relações jurídicas como igualitárias incorporadas ao direito constitucional de pretensão universalista" (Sinhoreto, 2010: 109). Seria como dizer que todos são iguais, desde que sejam tratados de forma absolutamente diferenciada. Justamente por isso, os procedimentos acionados pelos operadores situados dentro das instituições de justiça são permeados e, por que não dizer, orientados por "clivagens sociais, raciais, de gênero, culturais e religiosas e reservam tratamento diferenciado para tipos de conflitos e para indivíduos, conforme a posição que ocupam numa hierarquia de valores, pessoas, coisas e lugares" (Sinhoreto, 2010: 112).

Seguindo essa lógica, a escala mais elevada da justiça administraria os conflitos "protagonizados por pessoas de alto prestígio social" (Sinhoreto, 2010: 110), que lançam mão dos recursos disponíveis para proteger determinados direitos, garantir privilégios e, ainda, escapar de processos ou de formas de punição mais gravosas, como a privação da liberdade. Os casos de delação premiada de empresários - Odebrecht e JBS - seriam uma boa amostra desse argumento (Kant de Lima; Mouzinho, 2017).

Contudo, o problema que nos interessa diz respeito ao último nível da escala de intensidade de justiça. Como os operadores se orientam por características socioeconômicas para a construção social do crime e para a rotulação de alguém como criminoso, uma parcela da população vive amedrontada diante da possível ação policial e judicial que, longe de garantir determinados direitos, pode privá-la da liberdade, ou até mesmo da vida, como acontece nos constantes episódios de violência policial (Misse, 2010). Para esses sujeitos, o sistema de justiça nega, desde o princípio de sua atuação, o fundamento que orienta sua existência: a garantia de igualdade para além do status econômico (Marshall, 1967).

Neste artigo, argumentamos que essa ação seletiva desse sistema, excessivamente centrada sobre os pobres, pode ser analisada a partir da teoria dos rótulos, que problematiza como o crime é produzido pela interação entre aquele que tem legitimidade para acusar outrem como desviante (Velho, 2002) e o que não possui recursos institucionais para se proteger de tal acusação (Werneck, 2004). A acusação se dá por parte de um agente estatal, aquele que "detém não só o conhecimento, mas principalmente a competência para a interpretação correta da aplicação particularizada das prescrições gerais" (Kant de Lima, 2001: 109), sendo reificada por outros agentes, que produzem a incriminação e, por conseguinte, a punição de alguém por um delito que, muitas vezes, não se sabe ao certo como foi cometido (Misse, 2011). 0 acusado é aquele que possui algum tipo de marcação social que o inferioriza, sendo 
tradicionalmente visto como um cidadão de terceira classe (Carvalho, 2008) ou como um bandido que pode ser morto (Misse, 2010). Mais do que entender quais mecanismos são acionados na produção dessa justiça, interessa-nos apresentar uma crescente literatura nacional que problematiza o último nível de intensidade da justiça a que Sinhoretto (2010) se refere.

\section{FUNCIONAMENTO DO SISTEMA DE JUSTIÇA CRIMINAL: A ROTULAÇÃO COMO PONTO DE PARTIDA}

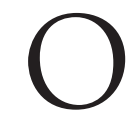

s estudos sobre a sociologia do desvio realizados por Becker constituem um dos marcos para a consolidação da teoria da rotulação como uma ferramenta para melhor compreensão dos processos que levam à conformação do crime e do criminoso (Werneck, 2014). 0 autor se concentrou em elucidar o processo de interação que leva a produção e aplicação de rótulos àqueles indivíduos considerados desviantes, procurando compreender por que nem todos os indivíduos que violam a lei são considerados criminosos, já que para ser um criminoso não basta cometer um crime, é necessário que a sociedade reaja de maneira negativa em relação ao indivíduo. Para essa abordagem, o desvio é socialmente construído, assim como o desviante é aquela pessoa a quem o rótulo foi aplicado com sucesso (Becker, 2008).

Se o criminoso, muitas vezes, se constrói em um processo de interação, no qual alguém aplica o rótulo de delinquente a outrem, é preciso entender como são construídas as definições jurídicas de crime, que servem para nortear a ação dos acusadores em relação aos acusados (Velho, 2002). Para Becker, nesse ponto, é necessário entender o papel desempenhado pelos empreendedores morais como agentes capazes de legitimar quais comportamentos serão considerados como desviantes, ressaltando duas categorias: reformadores cruzados e impositores de regras. Os reformadores cruzados constroem normas sociais por meio da lei jurídica, principalmente após a comoção da sociedade em relação a uma determinada ocorrência. Caso os reformadores cruzados obtenham sucesso ao instituir essa lei jurídica, cabe aos impositores de regras transformarem a letra morta da lei em uma realidade social e, consequentemente, lícita.

É a partir desse cheque em branco que a norma jurídica atribui às instituições responsáveis pelo controle social formal - isto é, policiais, promotores, defensores e juízes - que esses operadores passam a gozar de autonomia para agir diante de uma determinada situação, dizendo que a conduta prevista na norma, ocorreu enquadrando seu ator no rótulo de delinquente (Becker, 2008). Logo, a rotulação do indivíduo como desviante se torna consequência do empreendedorismo moral e de sua interação com um impositor de regras, que irá julgar determinado fato como crime e o sujeito como criminoso. 
Os estudos que usam a teoria da rotulação procuram entender como se dá a definição de uma regra penal (empreendedores morais), a identificação desta regra abstrata na realidade (impositores de regras), a classificação de alguém como criminoso e, depois, os efeitos desta marcação que inferioriza, o que resulta em segregação (prisão) e, até mesmo, a institucionalização de uma carreira desviante por parte daquele que foi rotulado como bandido. Logo, ao adotar a perspectiva da rotulação, a sociologia da administração da justiça passa a ser crítica do processo de estigmatização, por parte dos grupos dominantes, em relação àqueles com menor poder dentro da hierarquia social, que serão mais suscetíveis ao rótulo de criminoso. Desde a década de 1980, usando essa abordagem, os estudos brasileiros apontam como a raça, o sexo, a idade e a classe social são atributos para definir os indivíduos como criminosos, orientando a prática dos agentes policiais e do Poder Judiciário (Sinhoretto, 2014; Vargas, 2014; Azevedo, 2014).

Campos Coelho (1980), por exemplo, desmistificou a associação entre o crime e a pobreza, demonstrando que o Estado, por meio de mecanismos de poder e coerção, apreende os indivíduos pobres, colocando-os como mais propensos ao crime. Para ele, as classes estigmatizadas possuem maiores chances de serem rotuladas pelos policiais em suas operações rotineiras de vigilância, o que explicaria a sobrerrepresentação desses indivíduos nas estatísticas policiais. 0 autor demonstrou, ainda, como os crimes contra o patrimônio praticados por indivíduos pertencentes às classes baixas são tratados com maior rigidez pelo sistema de justiça criminal. Em contrapartida, o estelionato realizado por pessoas que possuem maior capital social, aqueles pertencentes às classes médias ou altas do estrato social, permanecem imunes ao Poder Judiciário.

Outro exemplo muito interessante para demonstrar a aplicabilidade da rotulação ao caso brasileiro é o que chamamos de crimes de "colarinho branco", praticados por pessoas que não condizem com o estereótipo do criminoso construído pela sociedade (Kant de Lima; Mouzinho, 2017). Assim sendo, suas práticas não são muitas vezes rotuladas como crimes e, por conseguinte, esses criminosos não são apreendidos pelos agentes da segurança pública. Isso faz com que a submissão desses indivíduos a processos criminais esteja mais condicionada à negociação com os poderes públicos, como demonstram os episódios recentes de delação premiada. Afinal, esses "criminosos" são indivíduos com status econômico elevado e ocupam cargos de prestígio, o que os imuniza ao estigma de bandidos, uma vez que estão protegidos dos mecanismos de coerção do sistema de justiça (Campos Coelho, 1978: 156).

Os estudos de Campos Coelho destacam a distinção existente no tratamento das pessoas envolvidas com o estelionato e com os crimes de "colarinho branco" em comparação 
aos crimes praticados por indivíduos das classes subalternas. Essa distinção é justificada pela capacidade operacional das organizações policiais em construir o perfil do criminoso atrelando a pobreza ao crime. Nesse raciocínio, o pobre se torna o estereótipo de alguém que comete crimes e, portanto, será alvo das intervenções policiais, enquanto o rico, sujeito ativo dos crimes contra o sistema financeiro e a administração pública, consegue passar despercebido pelos policiais que investigam a sua ação. Daí porque "as estatísticas oficiais constituem a definição cultural do que seja crime: esta definição é utilizada para diferenciar o criminoso oficial de tantos outros que violam a lei sem se tornarem legalmente criminosos, embora o comportamento de ambos seja o mesmo" (Campos Coelho, 1978: 154). A persistência ou a sobrevivência desses indivíduos, no que diz respeito ao processo de administração da justiça, e o consequente julgamento com mais severidade em relação ao estereótipo do criminoso são denominado pelo autor de "criminalização da marginalidade" (Campos Coelho, 1978: 158).

Se a Polícia Militar (ostensiva) produz dados sobre a criminalidade que não condizem com a realidade brasileira, posto que a ação policial busca prender pessoas de perfil estigmatizado com o propósito de incriminá-los para a resolução dos delitos, a Polícia Civil (investigativa) opera por meio da distribuição de "justiça por amostragem" (Paixão, 1982: 82). Paixão mostrou como os policiais se valem do poder do inquérito policial com a finalidade de obter informações e domesticar as classes com baixo status socioeconômico. Por isso, ao percorrerem a Cidade, os policiais procuram pessoas que correspondam ao perfil estigmatizado para fazer prevalecer a lei. De um lado, a distribuição de "justiça por amostragem" tem como objetivo captar clientes para o bem coletivo, retirando de circulação sujeitos que podem ser liberados mediante pagamento de propinas. De outro, a cultura organizacional indica como os policiais já possuem uma ideia formulada de quem são os culpados por crimes que ainda não foram registrados. Tais práticas policiais demonstram a conversão de pessoas nos artigos criminais, correlacionando os "indivíduos como suspeitos e suspeitos como indiciados" (Paixão, 1983: 42).

O trabalho de Paixão (1982) reifica que as estatísticas oficiais retratam uma concepção construída pela própria polícia sobre quem são os criminosos, percepção esta que termina por atrelar categorias de suspeitos a crimes reportados nas delegacias, fazendo com que os policiais ocupem seu tempo negociando com sua clientela quem será preso em cada situação. Além disso, o ritmo acelerado de apreensões de suspeitos pelas polícias não é o mesmo de resolução de casos pelo Poder Judiciário (Campos Coelho, 1986), sendo que o trabalho policial leva ao aumento de pessoas encarceradas provisoriamente e à superlotação das penitenciárias de sujeitos com o mesmo perfil: homens pretos e pobres (Sinhoretto, 2014). 
Soma-se a isso a indicação de Campos Coelho (1986), de que a forma de operação das polícias faz com que uma quantidade expressiva de processos seja instaurada com a consciência de que um número reduzido de pessoas será condenado, apontando para algo que verificamos na atualidade: o processo como pena. Trata-se de uma estratégia que visa a evitar a expressão "a polícia prende e a justiça solta", vista pelos operadores como um princípio fundamental de operacionalização do sistema de justiça criminal, uma validação da "disjunção entre o aparelho policial e a administração da justiça" (Campos Coelho, 1986: 333), o que leva à ratificação desse sistema como composto por "subsistemas frouxamente integrados".

A expressão significa que as diversas organizações que compõem o sistema de justiça criminal (polícias, Ministério Público, Defensoria Pública, Judiciário) obedecem a fundamentos distintos em relação às atividades por elas desenvolvidas, com destaque para os diferentes sistemas de verdades que orientam de forma dissonante a ação da polícia (inquisitorial) e do Judiciário (acusatorial) (Kant de Lima, 2004). Para evitar essa disjunção, a estratégia encontrada consiste em atrelar o crime à pobreza, viabilizada pela "justiça por amostragem", operada a partir dos estereótipos constituídos de que o criminoso é aquele indivíduo com baixo status socioeconômico e negro, sendo este o preferencialmente morto nas abordagens policiais, preso provisoriamente ou condenado à privação da liberdade. Diante disso, o sistema que funciona de forma altamente articulada, em uma espécie de linha de montagem (Sapori, 1995) acarreta profundas implicações sobre a institucionalização da democracia brasileira (Paixão, 1988), reforçando a cidadania disjuntiva (Holston; Caldeira, 1999).

Na linha de um sistema frouxamente articulado (Campos Coelho, 1986), mas que processa com extrema eficiência aqueles que merecem justiça de baixa intensidade (Sinhoretto, 2010), Adorno (1995) demonstrou como a seletividade policial é reforçada pela prestação jurisdicional desigual oferecida a réus de cor de pele distinta. 0 autor argumentou que os réus negros necessitam, com maior frequência, da assistência judiciária gratuita e como os defensores públicos possuem uma atuação limitada à "letra fria da lei" , pois não se empenham em elaborar defesas contundentes por meio de provas documentais, periciais e testemunhais. Eles não são traquejados o suficiente para lograr a absolvição do réu ou para atenuar a pena, fato que acarreta em uma maior probabilidade de condenação dos réus negros. Em contrapartida, os réus brancos possuem maiores vantagens e privilégios, pois contratam advogados particulares que possuem vasta experiência, logrando a isenção da responsabilização penal. Adorno concluiu que o direito à ampla defesa não está garantido para os réus negros, visto que eles possuem dificuldades para acessar os seus direitos por meio de defesa qualificada, bem como são mais vulneráveis à violência policial e à arbitrariedade do sistema de justiça. 
As desigualdades socioeconômicas distribuídas nas mais diversas hierarquias de poder e a atuação policial centrada em uma clientela específica na busca de "criminosos" provoca a vulnerabilidade das classes mais pobres e maior vigilância por parte dos órgãos responsáveis pelo controle social, o que tem implicações imediatas na composição da população prisional, em termos de sexo, idade e grau de escolaridade (Sinhoretto; Lima; Bueno, 2015). Se, de um lado, a Constituição prevê princípios de garantia de cidadania, por outro, o sistema de justiça criminal classifica e discrimina os indivíduos que possuem menor poder aquisitivo, reservando a eles a escala mais baixa de intensidade de justiça (Sinhoretto, 2010). É por intermédio da atuação desse sistema que os cidadãos brasileiros podem ser divididos em duas categorias: os civilizados e os marginais. Aos agentes da segurança pública cabe a tarefa de selecionar os indivíduos que são considerados marginais mesmo que eles estejam em acordo com as regras jurídicas estabelecidas em nosso País.

Diante desses estudos, constata-se que o poder da polícia em atuar como impositora de regras faz com que, preferencialmente os indivíduos carentes de imunidades institucionais sejam rotulados como criminosos, o que torna a população apresentada pela polícia à justiça composta, majoritariamente, por homens jovens, pobres, pretos e pardos. Ocorre que, uma vez "nas malhas da justiça", esse grupo vai progressivamente se tornando ainda mais homogêneo, já que os padrões de seleção terminam por diferenciar os indivíduos apresentados ao Judiciário em razão de sua origem social, fazendo com que este perfil receba um serviço de pior qualidade que, inevitavelmente, levará à prisão.

Um leitor mais atento poderia destacar que as análises apresentadas nesta seção foram realizadas no período ditatorial. Com a transição daquele regime para o democrático, esperava-se que as arbitrariedades cometidas pelos policiais durante a ditadura diminuíssem, tornando os serviços da justiça mais acessíveis aos desfavorecidos economicamente e, dessa maneira, a violência como mecanismo de solução de conflitos nas ruas se tornaria algo do passado. No entanto, a promessa democrática não foi capaz de criar raízes nessa área: no transcorrer da década de 1990, o País se modernizou, a democracia procedimental se institucionalizou e a violência encontrou terreno fértil para sua multiplicação, impondo desafios ao sistema de justiça criminal.

\section{A RETOMADA DA TEORIA DA ROTULAÇÃO: O EFEITO ACUMULADO DO ESTEREÓTIPO NO FLUXO DO SISTEMA DE JUSTIÇA}

tualmente, a teoria da rotulação é uma das abordagens mais mobilizadas para o en-
tendimento de como opera o sistema de justiça criminal (Paes; Ribeiro, 2015), apesar 
de ter sido uma perspectiva bastante criticada nos anos 1980, nos Estados Unidos, uma vez que ela não consegue explicar a vitimização diferencial de pretos e pardos por crimes dolosos contra a vida, situações nas quais o delito não se constrói a partir de uma interação entre os impositores de regra e o suposto criminoso. Naquele momento, várias cidades americanas apresentavam uma explosão de delitos violentos e, para alguns autores, parecia temerário atribuir à interação social a responsabilidade sob a produção das elevadas taxas delitivas (Akers, 1968).

Por outro lado, a perspectiva da rotulação foi vista como importante para se entender as carreiras desviantes de delitos de menor potencial ofensivo, teoricamente praticados por qualquer indivíduo (furto e sonegação fiscal), conclusões essas ancoradas nas surveys de autorreportagem (Akers, 2011). Esses estudos demonstram que apenas indivíduos com um determinado perfil caíam nas malhas da justiça, sendo que os demais permaneciam como desviantes ocultos aos olhos das agências de controle. Nessa dimensão estão os autores que compreendiam a carreira criminosa como efeito de rotulagem, isto é, ao ser rotulado como criminoso, o indivíduo teria menos oportunidades no mercado de trabalho, o que poderia aumentar o comportamento antissocial por parte dos sujeitos assim marcados (Liberman; Kirk, 2014).

É nesse debate sobre a aplicabilidade ou não da teoria da rotulação para o entendimento dos processos que levam à constituição do crime e do criminoso que essa perspectiva começa a ser redescoberta no Brasil. As concepções reinantes sobre o crime no País foram intensamente influenciadas pela falácia da associação entre crime e pobreza, que partiam do pressuposto que a solução para o problema da delinquência perpassava por melhoria de políticas públicas e redistribuição de renda (Zaluar, 1999). 0 ingresso da labeling approach inaugurou uma área de estudos sobre o sistema de justiça criminal brasileiro que, ainda hoje, termina por reforçar, a partir de evidências empíricas, as predições de tal perspectiva teórica.

A partir da década de 1990, a discussão sobre como a perspectiva de Becker contribuiria para uma melhor compreensão das injustiças dentro da área criminal se concentrava na aplicação das leis de forma discriminatória em estereótipos construídos pelos operadores daquele sistema (Vargas, 2014). Esse é um momento no qual a criminalidade violenta assume uma nova configuração, por meio do comércio ilegal de drogas e, por conseguinte, da disputa travada entre o Estado e os "traficantes". Nesse mercado, agentes do Estado e comerciantes de substâncias ilegais se organizam a partir de uma rede de troca de favores e de mecanismos de vingança, o que, muitas vezes, termina por transbordar para todos os que residem nas áreas periféricas nas quais ocorre essa negociação/disputa, com a finalidade de fazer prevalecer 
valores e normas instituídos pelos grupos criminosos, terminando por conformar um novo tipo de sociabilidade, a violenta (Machado da Silva, 2004). Essa conjuntura e a discriminação por parte do sistema de justiça criminal em relação às classes subalternas produzem efeitos perversos no que diz respeito à vigilância cerrada de determinados segmentos populacionais, reforçando as barreiras que dificultam o acesso à justiça e potencializam penalização das camadas de baixo status socioeconômico (Zaluar, 1999).

Para entendimento de como essa acumulação social da violência passa a ser administrada pelas agências do sistema de justiça criminal, Misse (2008) constrói alguns operadores analíticos que ressaltam como se dá a construção social do crime, explicando os motivos pelos quais os indivíduos das classes subalternas possuem maior probabilidade de serem acusados de criminosos. 0 primeiro operador analítico proposto pelo autor consiste na construção do fato criminoso ou na reação moral da sociedade que define os critérios para que um ato seja considerado como crime, sendo este marcador denominado de criminalização, retomando o empreendedorismo moral formulado por Becker. 0 segundo operador construído pelo autor é a criminação, que diz respeito às formas e técnicas a partir das quais os impositores de regras acoplam a lei a uma determinada conduta, isto é, trata-se do momento em que uma autoridade afirma que o cidadão realizou uma conduta prevista no Código Penal.

Após a criminação, tem início a incriminação do suspeito pelas informações coletadas para subsidiar o registro policial e, depois, a abertura do inquérito policial, que procurará, por meio das testemunhas e de evidências intersubjetivas, afirmar quem é o criminoso, indiciando-o (Misse, 2008). Essa fase policial é inquisitorial, sem contraditório, posto que não há acusação: é muito comum que a polícia tire alguma vantagem do suspeito com o propósito de "armar o processo" com algumas práticas institucionalizadas, como a legitimidade da violência, a autorização da presença dos advogados particulares para acompanhar os inquéritos e o arquivamento ou prosseguimento das investigações, de acordo com a posição do indivíduo na hierarquia social (Kant de Lima, 1997: 175).

Kant de Lima (2004) procura entender o fluxo do sistema de justiça penal a partir de modelos inquisitoriais e acusatoriais que, longe de promover os direitos civis entre os cidadãos brasileiros, termina por negá-los. Para ele, os padrões de seleção e filtragem são operados a partir da articulação de diferentes "sistemas da verdade" que são orientados pelos princípios constitucionais de presunção da inocência, o direito à defesa e o direito ao silêncio, os quais, por sua vez, têm interpretações diferenciadas, dependendo de quem são os criminosos (Kant de Lima, 1997: 173). Trata-se, então, de uma abordagem que reforçaria o pressuposto da teoria da rotulação (indivíduos diferentes são etiquetados de forma distinta), mas também se dis- 
tanciaria dela, posto que não é o rótulo que leva à segregação, mas a ausência de inserção social que ocasiona a classificação estigmatizante, produzindo uma marcação que inferioriza o sujeito.

A denúncia do promotor marca o início do processo judicial, da fase acusatorial, na qual alguém se torna formalmente acusado pela prática de um crime, já que a polícia tem poder apenas para indiciar o suspeito. A incriminação pela denúncia retoma a "letra da lei", oferecendo legitimidade à continuação da acusação no âmbito do processo criminal por meio de provas periciais, documentais e testemunhais, que permitem construir a "verdade" da acusação (Kant de Lima, 2004). Nesse diapasão, o processo penal pode ser visto como a acumulação da incriminação iniciada na polícia, mas sem a perspectiva de (des)incriminar determinada parcela de indivíduos levados à justiça: se o pobre cai nas malhas da justiça, condenado ele está (Sinhoretto, 2014). Por isso, logo no início da instrução, o juiz adverte "o acusado de que 'seu silêncio poderá resultar em prejuízo de sua própria defesa', algo que parece colocar-se nitidamente em contradição com o direito ao silêncio do dispositivo constitucional" (Kant de Lima, 1997: 175).

Ao reconstituir o fluxo de procedimentos que orienta o funcionamento do sistema de justiça criminal, Kant de Lima (1987) afirma que a construção judicial do crime se funda em um "mosaico de verdades", conformado a partir de procedimentos diferenciados de produção da verdade, determinados pelos policiais e pelos operadores do direito a partir de uma série de depoimentos que reforçam, progressivamente, a rotulação inicial de alguém pela prática do delito. Por isso, ele afirma que, no Brasil, não há uma saída para a resolução dos conflitos a partir do consenso entre as três instâncias, pois as verdades são produzidas por critérios diferenciados, sem qualquer comunicação entre eles. A verdade produzida pela polícia (criminação) é a responsável por transformar o crime em uma realidade, pois, a partir da incriminação de alguém como suposto criminoso, ela se torna mais viável.

Para Misse (2008), a questão é um pouco mais complexa, dado que o sistema de justiça criminal brasileiro não opera a partir da criminalização, para depois seguir com a criminação, culminando com a incriminação. Pelo contrário: o sistema funciona a partir da sujeição criminal que se qualifica pela seleção dos indivíduos que compõem o tipo social propenso a cometer crimes. Assim, o sistema primeiro escolhe o indivíduo e depois investiga quais foram os crimes que ele cometeu. Nessa dimensão, o autor reforça a teoria da rotulação, destacando que a acusação é um processo de interação social, cujo resultado está relacionado à forma de imposição do poder de um indivíduo sobre outro.

Ocorre que essa escolha de potenciais indivíduos delinquentes não é ampla, sendo bastante concentrada entre aqueles que compartilham o estereótipo de bandido (Misse, 2010). 
Como a acusação é um processo de interação social entre os indivíduos, ela termina por ser estruturada como algo anterior ao fato criminoso. Essa é a chave para o entendimento das dissonâncias existentes entre a abordagem de Misse (2008) e a proposta da teoria da rotulação na versão reformulada de Becker. Nas palavras do autor:

De um ponto de vista formal, a sujeição criminal refere-se a um processo social pelo qual se dissemina uma expectativa negativa sobre indivíduos e grupos, fazendo-os crer que essa expectativa não só é verdadeira como constitui parte integrante de sua subjetividade. 0 conteúdo de sentido dessa expectativa não é apenas um atributo desacreditador, como no estigma, nem decorre apenas de um processo de rotulação de um comportamento desviante de primeiro grau (como no desvio primário), antes parece ser determinante desses ou, ao menos, enlaçado a esses. Refere-se a um set institucionalizado denominado "Código Penal", historicamente construído e administrado monopolicamente pelo Estado, que se confunde inteiramente com o moderno processo de criminalização. (...) Na sujeição criminal, o crime é reificado no suposto sujeito autor de crimes (Misse, 2014: 170).

A partir dos operadores analíticos (criminalização, criminação, incriminação e sujeição criminal), Michel Misse se torna uma figura-chave para entendermos a aplicação da teoria da rotulação no funcionamento do sistema de justiça criminal brasileiro nos últimos anos, pois ele sublinha como o crime é um acontecimento social que se constrói a partir da interação entre o acusado (rotulado) e acusador (policiais e operadores do direito). A suspeição constante, aplicada a certos indivíduos, aciona uma série de engrenagens como forma de garantir a incriminação sucessiva do sujeito cujas características se enquadram no estereótipo do "bandido", culminando em sua condenação à pena privativa de liberdade ou à execução extrajudicial pelas mãos das polícias (Misse, 2010). Ao mesmo tempo, essa perspectiva se distancia da abordagem de Becker, porque "o rótulo e o estigma, nesses casos, são efeitos, ou se articulam à sujeição criminal, mas não lhe são causas, não lhe são logicamente anteriores" (Misse., 2014: 170). Afinal, é a sujeição criminal que leva à incriminação preferencial de uma classe de indivíduos como delinquentes, bloqueando-lhes o acesso às instituições de justiça, 0 que deterioraria a identidade de cidadãos entre tais sujeitos.

Em síntese, a rotulação de um indivíduo como criminoso está intrinsecamente relacionada ao processo de sujeição criminal $\nabla$ o indivíduo possui o estereótipo de bandido procurado pelos policiais para fechar os inquéritos, definindo um culpado (Mlsse, 2011). Nesse contexto, a sujeição criminal explica a problemática da desconfiança do trabalho policial pelas comunidades de baixa renda, visto que a suspeição dos moradores de periferia antecede, inclusive, o fato criminoso. Mais uma vez, destaca-se que o controle social realizado pelos policiais não pressupõe a igualdade de direitos e discrimina indivíduos pobres e negros. Assim, apesar 
das organizações policiais internalizarem um discurso democrático, galgado na gramática do policiamento comunitário, suas práticas discricionárias e inquisitoriais irão oferecer poder para que seus funcionários possam construir e reificar o estereótipo do criminoso, resultando na incriminação preferencial dos suspeitos que possuem baixo status socioeconômico e a cor da pele escura (Paes; Ribeiro, 2015).

As pesquisas empíricas sobre o tema parecem validar a ideia de que o sistema de justiça criminal opera a partir da sujeição criminal (Vargas, 2014). Os resultados obtidos pela revisão de Sinhoretto (2014) mostram que os indivíduos abordados pela polícia são, preferencialmente, do sexo masculino, pretos e pardos, jovens e com pouca instrução, sujeitos estes que possuem elevadas chances de serem processados e condenados. Ou seja, são os que compartilham os estereótipos típicos da sujeição criminal que possuem mais chances de indiciamento, acusação e condenação, "sobrevivendo" a todas as fases do fluxo de processamento (Vargas, 2014).

0 caleidoscópio operado a partir da labeling theory mostra que a administração da justiça no Brasil é, em verdade, a institucionalização de práticas desiguais (Azevedo, 2014), organizadas de acordo com a classe do cidadão (Carvalho, 2008), distanciando-se do processo e julgamento do fato ocorrido (Vargas, 2014). Essa perspectiva, com destaque para os conceitos desenvolvidos por Misse (2014), tem sido utilizada para subsidiar uma série de estudos sobre o funcionamento da justiça criminal brasileira, no que tange às práticas das organizações policiais e à desarticulação entre os princípios democráticos que orientam a sua constituição e o seu real funcionamento do sistema de justiça (Paes; Ribeiro, 2015), algo que vai na contramão dos pressupostos do Estado Democrático de Direito (Kant de Lima, 2004). Ademais, os estudos atuais contribuem para uma maior reflexão sobre a democratização da sociedade brasileira, ao demonstrar como a justiça opera de forma diferente dependendo de quem é colocado diante das instituições desse Estado (Sinhoretto, 2010). A criminação pode ser a mesma, mas a incriminação será essencialmente diversa em razão do sexo, da idade, da cor da pele e, especialmente, do local de moradia, já que essa última categoria é extremamente importante no acionamento da sujeição criminal (Misse, 2011).

\section{CONSIDERAÇÕES FINAIS}

$\mathrm{D}$ esde a década de 1980, uma série de estudos em relação ao funcionamento seletivo do sistema de justiça criminal brasileiro têm sido realizados a partir da perspectiva formulada por Becker, resultante do processo de interação entre aqueles que desejam impor determinadas regras e aqueles que praticam a ação descrita de um delito. Ele dissertou sobre o processo de criação de regras e sua imposição, destacando as possíveis desigualdades 
associadas a essa dinâmica e afirmando que nem todos os indivíduos possuem a mesma chance de se conformarem em uma regra Jurídica proibitiva, inscrita no Código Penal. Para isso, é necessário que um empreendedor moral esteja disposto a levantar a bandeira da criminalização de um comportamento, direcionando a demanda ao Legislativo e inscrevendo essa conduta social no rol das leis penais. Assim sendo, a lei deve se encaixar a um determinado comportamento desviante para que a sociedade reconheça a existência do delito. Não basta que um dado indivíduo infrinja a regra. É preciso que alguém com autoridade reconhecida diga publicamente que aquela ação é um desvio, rotulando-a como crime e o responsável por sua prática como criminoso.

0 presente artigo procurou indicar como a labeling theory tem contribuído para a constituição de diversas análises empíricas sobre os padrões de seleção que marcam a operação do sistema de justiça criminal no País, reforçando a estigmatização de negros, pobres e moradores de vilas e favelas como criminosos. A partir dos anos 1990, Misse inova na forma como a rotulação poderia ser percebida de maneira diferenciada no caso brasileiro. Com base na aplicação da sujeição criminal, o autor constata por que os homens jovens, pobres e de cor escura são os que apresentam as maiores probabilidades de serem autuados pela Polícia Militar, investigados pela Polícia Civil, acusados pelo Ministério Público e sentenciados pelo Judiciário. Nesse ínterim, a sobrevivência do criminoso significa não escapar em quaisquer dessas fases de processamento, sendo sentenciado e condenado na fase final. 0 trabalho de Misse passa a ser o ponto de partida de uma diversa produção sobre o sistema de justiça criminal ao reforçar que a única forma de se compreender como a justiça é interpretada pelas agências que operam as ações de prevenção e repressão à criminalidade é a partir do entendimento das práticas de seus operadores.

A revisão de estudos apresentada no artigo ressaltou como a operação do sistema de justiça criminal é seletiva, possibilitando entender os motivos pelos quais a população prisional brasileira é composta, majoritariamente, por homens jovens, de cor preta ou parda e de baixa escolaridade, bloqueando a promoção da cidadania civil (Marshall, 1967) ao longo do fluxo de processamento. Em especial, os estudos sobre o funcionamento desse sistema, realizados após a última transição democrática, apontam que a justiça é de baixa intensidade para uma ampla parcela da população e de alta intensidade para uma pequena elite (Sinhoretto, 2010).

Com isso, os conflitos dos pobres são tratados de forma mais severa e letal, verificado pelo descompasso entre o ideal de democracia e a realidade construída por instituições que deveriam ser encarregadas da produção de justiça na sociedade brasileira. Isso posto, assistimos à consolidação da cidadania disjuntiva (Holston; Caldeira, 1999), dado que há 
um enorme descompasso entre as disposições legais e a realidade institucionalizada pelas organizações policiais, responsáveis por decidir quem cairá nas malhas da justiça, a partir da sujeição criminal.

\section{NOTA}

1 Neste artigo, não serão apresentados dados empíricos sobre o funcionamento seletivo do sistema de justiça criminal, posto que esta abordagem foi longamente revista por Vargas (2014) com a apresentação de resultados bastante palpáveis sobre como ocorre a seletividade. Será descrito, assim, um estado da arte sobre as pesquisas que se utilizam da labeling theory para entender o padrão de operação do sistema de justiça criminal.

\section{REFERÊNCIAS BIBLIOGRÁFICAS}

ADORNO, Sérgio. Discriminação racial e justiça criminal em São Paulo. Novos Estudos, São Paulo, n. 43, 1995.

AKERS, Ronald L. Problems in the sociology of deviance: social definitions and behavior. Social Forces, v. 46, n. 4, 1968.

Social learning and social structure: a general theory of crime and deviance. Nova Jersey: Transaction Publishers, 2011.

AZEVEDO, Rodrigo. Sociologia da administração da Justiça. In: LIMA, Renato Sérgio de; RATTON, José Luiz; AZEVEDO, Rodrigo Ghiringhelli (Org.). Crime, segurança e justiça no Brasil. São Paulo: Contexto, 2014.

BECKER, Howard Soul. Outsiders: estudos de sociologia do desvio. 1. ed. Rio de Janeiro: Zahar, 2008 [1963].

CALDEIRA, Teresa P. R.; HOLSTON, James. Democracy and violence in Brazil. Comparative studies in society and history. Society and History, v. 41, n. 4, 1999.

CAMPOS COELHO, Edmundo. A criminalização da marginalidade e a marginalização da criminalidade. Revista de Administração Pública, Rio de Janeiro, v. 12, n. 2, 1978.

. A administração da justiça criminal no Rio de Janeiro: 1942-1967. Dados, Rio de Janeiro, v. 29, n. 1, 1986.

. Sobre sociólogos, pobreza e crimes. Dados, Rio de Janeiro, v. 23, n. 3, 1980.

CARVALHO, José Murilo. Cidadania no Brasil: o longo caminho. Rio de Janeiro: Civilização Brasileira, 2008.

HOLSTON, James. Cidadania insurgente: disjunções da democracia e da modernidade no Brasil. São Paulo: Companhia das Letras, 2013.

KANT DE LIMA, Roberto. Polícia e exclusão na cultura judiciária. Revista de Sociologia da USP, São Paulo, v. 9, n. 1, 1997b.

. Carnavais, malandros e heróis: o dilema brasileiro do espaço público. In: GOMES, Laura Graziela; BARBOSA, Lívia; DRUMMOND, Augusto (Org.). O Brasil não é para principiantes. Rio de Janeiro: FGV, 2001.

. Direitos civis e direitos humanos: uma tradição judiciária pré-republicana? São Paulo em Perspectiva, v. 18, n. 1, 2004. 
; MOUZINHO, Glaucia Maria Pontes. Produção e reprodução da tradição inquisitorial no Brasil: entre delações e confissões premiadas. Dilemas: Revista de Estudos de Conflito e Controle Social, v. 9, n. 3, 2017.

LIBERMAN, Akiva M.; KIRK, David S.; KIM, Kideuk. Labeling effects of first juvenile arrests: secondary deviance and secondary sanctioning. Criminology, v. 52, n. 3, 2014.

LIMA, Renato Sérgio de; SINHORETTO, Jacqueline; BUENO, Samira. A gestão da vida e da segurança pública no Brasil. Sociedade e Estado, Brasília, v. 30, n. 1, 2015.

MACHADO DA SILVA, Luiz Antonio. Sociabilidade violenta: por uma interpretação da criminalidade contemporânea no Brasil urbano. Sociedade e Estado, Brasília, v. 19, n. 1, 2004.

MARSHALL, Thomas Humphrey. Cidadania, classe social e status. Rio de Janeiro: Zahar, 1967.

MISSE, Michel. Crime, sujeito e sujeição criminal: aspectos de uma contribuição analítica sobre a categoria "bandido". Lua Nova, São Paulo, v. 79, 2010.

Sobre a construção social do crime no Brasil: esboços de uma interpretação. In: (Org.).

Acusados e acusadores: estudos sobre ofensas, acusações e incriminações. Rio de Janeiro: Revan, 2008.

0 papel do inquérito policial no processo de incriminação no Brasil: algumas reflexões a partir de uma pesquisa. Sociedade e Estado, Brasília, v. 26, n. 1, 2011.

Sujeição criminal. In: LIMA, Renato Sérgio de; RATTON, José Luiz; AZEVEDO, Rodrigo Guiringhelli (Org.). Crime, segurança e justiça no Brasil. São Paulo: Contexto, 2014.

PAES, Vívian Gilbert Ferreira; RIBEIRO, Ludmila Mendonça Lopes. Produção acadêmica sobre práticas de segurança pública e justiça criminal: estudos empíricos sobre instituições, interesses, decisões e relações dos operadores com o público. Confluências, Niterói, v. 16, n. 3, 2015.

PAIXÃO, Antônio Luiz. A organização policial numa área metropolitana. Revista de Ciências Sociais, Rio de Janeiro, v. 25, n. 1, 1982.

Crime, controle social e consolidação da democracia: as metáforas da cidadania. In: REIS, F.; O’DONNEL, G. (Ed.). A democracia no Brasil. São Paulo: Vértice, 1988.

0 problema da polícia. In: IUPERJ. Violência e participação política no Rio de Janeiro. Rio de Janeiro, 1995. n. 91. (Série Estudos).

SAPORI, Luís Flávio. A administração da justiça criminal numa área metropolitana. Revista Brasileira de Ciências Sociais, v. 10, n. 29, 1995.

SHIRLEY, Robert Weaver. Antropologia jurídica. São Paulo: Saraiva, 1987.

SINHORETTO, Jacqueline. Campo estatal de administração de conflitos: múltiplas intensidades da justiça. Anuário Antropológico, Brasília, v. II, n. 2009, 2010.

Seletividade penal e acesso à justiça. In: LIMA, Renato Sérgio de; RATTON, José Luiz; AZEVEDO, Rodrigo Ghiringhelli (Org.). Crime, segurança e justiça no Brasil. São Paulo: Contexto, 2014.

VARGAS, Joana Domingues. Fluxo do sistema de justiça criminal. In: LIMA, Renato Sérgio de; RATTON, José Luiz; AZEVEDO, Rodrigo Guiringhelli (Org.). Crime, segurança e justiça no Brasil. São Paulo: Contexto, 2014. 
VELHO, Gilberto. Becker, Goffman e a antropologia no Brasil. Ilha: Revista de Antropologia, Florianópolis, v. 4, n. 1, 2002.

WERNECK, Alexandre. Teoria da rotulação. In: LIMA, Renato Sérgio de; RATTON, José Luiz; AZEVEDO, Rodrigo Ghiringhelli (Org.). Crime, segurança e justiça no Brasil. São Paulo: Contexto, 2014.

ZALUAR, Alba. Violência e crime. In: MICELI, Sérgio (Org.). O que ler na ciência social brasileira (1970-1995): antropologia. Sumaré: Anpocs; Brasília: Capes, 1999. v. 1, p. 13-107. 